\title{
A case of respiratory muscle weakness due to cytochrome c oxidase enzyme deficiency
}

\author{
A. O'Brien*, M. Blaivas**, J. Albers**, J. Wald**, C. Watts*
}

A case of respiratory muscle weakness due to cytochrome c oxidase enzyme deficiency. A. O'Brien, M. Blaivas, J. Albers, J. Wald, C. Watt. @ERS Journals Ltd 1998.

ABSTRACT: Mitochondrial myopathy is a rare cause of dyspnoea and respiratory failure, usually presenting in infancy. We describe a $27 \mathrm{yr}$ old woman with a partial cytochrome c oxidase enzyme deficiency causing respiratory muscle weakness and respiratory failure. The onset was acute, with no preceding respiratory symptoms. The patient was successfully treated with bilevel positive airway pressure therapy. Eur Respir J., 1998; 12: 742-744.
*University of Michigan Medical Center, Division of Pulmonary and Critical Care Medicine, and **Depts of Pathology and Neurology, Ann Arbor, MI, USA.

Correspondence: A. O'Brien, Division of Pulmonary and Critical Care Medicine, Box 0360, 3916 Taubman Center, University of Michigan Medical Center, 1500 East Medical Center Drive, Ann Arbor, MI 48109, USA. Fax: 17349365048

Keywords: BiPAP, mitochondrial myopathy, pulmonary hypertension, respiratory failure

Received: October 271997

Accepted after revision April 91998
Cytochrome c oxidase (COX) is a complex mitochondrial enzyme involved in oxidative phosphorylation. COX deficiency can result in a myopathy. We describe a patient with acute respiratory failure and pulmonary hypertension secondary to a partial COX enzyme deficiency. This is one of four reported cases with isolated late-onset COX deficiency involving muscle, sparing ocular or central nervous system function. This patient also illustrates the need to consider neuromuscular weakness in the differential diagnosis of dyspnoea, respiratory failure and pulmonary hypertension. Finally, the effectiveness of bilevel positive airway pressure (BiPAP) therapy in respiratory failure due to a myopathy is demonstrated.

\section{Case report}

A $27 \mathrm{yr}$ old woman was admitted to another hospital after 3 months of progressive dyspnoea on exertion. She was short of breath on walking up $<1$ flight of stairs. She also complained of coughing and some wheezing. Previous treatment included numerous courses of antibiotics and systemic corticosteroids without benefit. The patient had no prior illnesses; she was on no other medications, and had no known environmental exposures. She had never smoked cigarettes or abused alcohol or drugs. Her family history was noncontributory.

Physical examination revealed the blood pressure to be $127 / 64 \mathrm{mmHg}$, heart rate 98 beats $\cdot \mathrm{min}^{-1}$, respiratory rate 23 breathes $\cdot \mathrm{min}^{-1}$. The patient was afebrile and in mild respiratory distress. There was evidence of pulmonary hypertension. A chest examination revealed limited thoracic movement and diminished breath sounds without wheezing or crackles. The patient had 3+ peripheral oedema. The neuromuscular exam was normal, including eye move- ments. Initial arterial blood gas analysis on room air: $\mathrm{pH}$ 7.36, $\mathrm{O}_{2}$ tension in arterial blood $\left(\mathrm{Pa}_{2} \mathrm{O}_{2}\right) 4.1 \mathrm{kPa}(31$ $\mathrm{mmHg}), \mathrm{CO}_{2}$ tension in arterial blood $\left(\mathrm{Pa}_{2} \mathrm{CO}_{2}\right) 9.4 \mathrm{kPa}(71$ $\mathrm{mmHg}$ ). The routine laboratory evaluation was unremarkable. The chest radiograph revealed cardiomegaly with central pulmonary vascular engorgement. Supplemental oxygen was administered, and the $\mathrm{Pa}_{\mathrm{a}} \mathrm{O}_{2}$ rose to $9.0 \mathrm{kPa}(68$ $\mathrm{mmHg}$ ); however, the $\mathrm{Pa}_{\mathrm{a}} \mathrm{CO}_{2}$ progressively rose, ultimately requiring ventilatory support. Evaluation of the pulmonary hypertension included the following: cardiac ultrasound showed marked right atrial and ventricular enlargement, with moderate tricuspid regurgitation and normal left ventricular function. There was no evidence of intracardiac shunts. The ventilation-perfusion lung scan and lower extremity duplex ultrasound were normal. Right heart catheterization revealed a pulmonary artery pressure of 97/52 $\mathrm{mmHg}$, cardiac output/index 7/3.5 L· $\mathrm{min}^{-1}$, pulmonary capillary wedge pressure $18 \mathrm{mmHg}$, central venous pressure $27 \mathrm{mmHg}$, systemic vascular resistance 881 dyne $\cdot \mathrm{s}^{-1} \cdot \mathrm{cm}^{-5}$, pulmonary vascular resistance $576 \mathrm{dyne} \cdot \mathrm{s}^{-1} \cdot \mathrm{cm}^{-5}$. The patient was successfully extubated 2 days later and transferred to our hospital.

Further evaluation at our hospital included: arterial blood gases, which showed $\mathrm{pH} 7.27, \mathrm{~Pa}, \mathrm{O}_{2} 11.0 \mathrm{kPa}(83 \mathrm{mmHg})$, $\mathrm{Pa}, \mathrm{CO}_{2} 10.5 \mathrm{kPa}(79 \mathrm{mmHg})$ on $5 \mathrm{~L} \cdot \mathrm{min}^{-1} \mathrm{O}_{2}$. Pulmonary function tests (PFTs): forced vital capacity (FVC) $1.02 \mathrm{~L}$ (26\% predicted), forced expiratory volume in one second (FEV1) $0.89 \mathrm{~L}$ (28\% pred), FEV1/FVC\% $87 \%$ pred, carbon monoxide diffusing capacity of the lung (DL,CO) 11.88 $\mathrm{mL} \cdot \mathrm{min}^{-1} \cdot \mathrm{mmHg}^{-1}(46 \%$ pred $)$, and carbon monoxide transfer coefficient (KCO) (DL,CO/alveolar volume $(V \mathrm{~A}) 6.18$ $\mathrm{mL} \cdot \mathrm{min}^{-1} \cdot \mathrm{mmHg}^{-1} \mathrm{~L}^{-1}(130 \%$ pred). A high-resolution computed tomography (CT) scan of her lungs showed no evidence of any intraparenchymal disease. A sleep study ruled 
out sleep apnoea, but there were repetitive significant falls in the $\mathrm{Sa}_{\mathrm{a}} \mathrm{O}_{2}$ during sleep, even with supplemental oxygen. Given the presence of a restrictive ventilatory defect without parenchymal lung disease, further studies focusing on neuromuscular weakness indicated the following: 1) potassium, magnesium, calcium, creatinine kinase, thyroid function tests and lactic acid were measured and were nor$\mathrm{mal}$; 2) the maximum inspiratory pressure (MIP), measured at residual volume (RV), was $\left.-20 \mathrm{cmH}_{2} \mathrm{O} ; 3\right)$ a decreased diaphragmatic motion was observed on fluoroscopy; 4) lowamplitude phrenic nerve evoked-responses were noted; 5) electromyography (EMG) of the diaphragm and extremity muscles was normal, as were nerve conduction studies, including tests of neuromuscular transmission; 6) a muscle biopsy revealed coarse mitochondrial staining with ragged red-like fibres (fig. 1), elevated intracellular lipids (fig. 2), and misshapened mitochondria with disoriented cristae in electron micrographs, all suggestive of a mitochondrial metabolic myopathy. Further biochemical studies revealed a partial cytochrome c oxidase (COX) enzyme deficiency (table 1). As part of the evaluation, the patient also underwent a cardiopulmonary exercise study. This demonstrated the presence of a mixed ventilatory and circulatory defect, consistent with her respiratory muscle weakness and impaired oxygen utilization in the peripheral musculature.

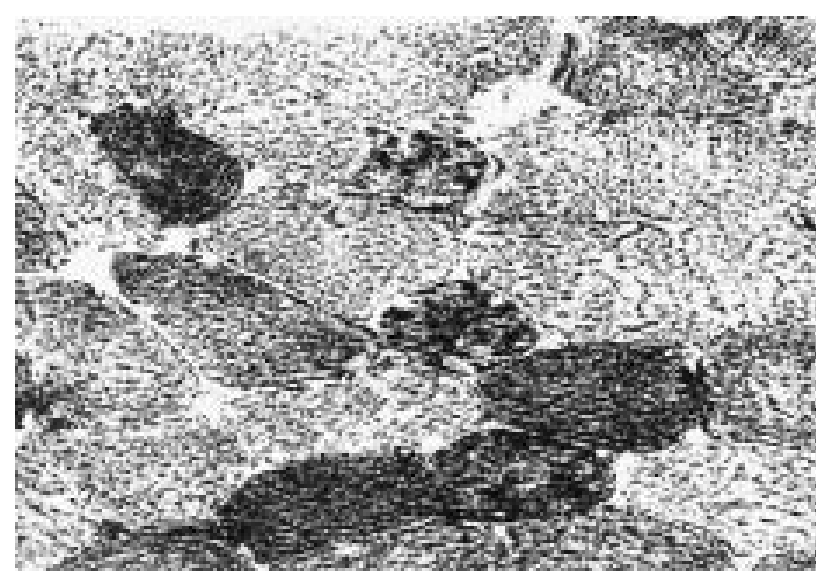

Fig. 1. - Photomicrograph of muscle biopsy, showing coarse cytoplasmic staning and thickened sarcolemma of muscle fibres (nicotinamide adenine dinucleotide stain). (Internal scale bar $=30 \mu \mathrm{m}$.)

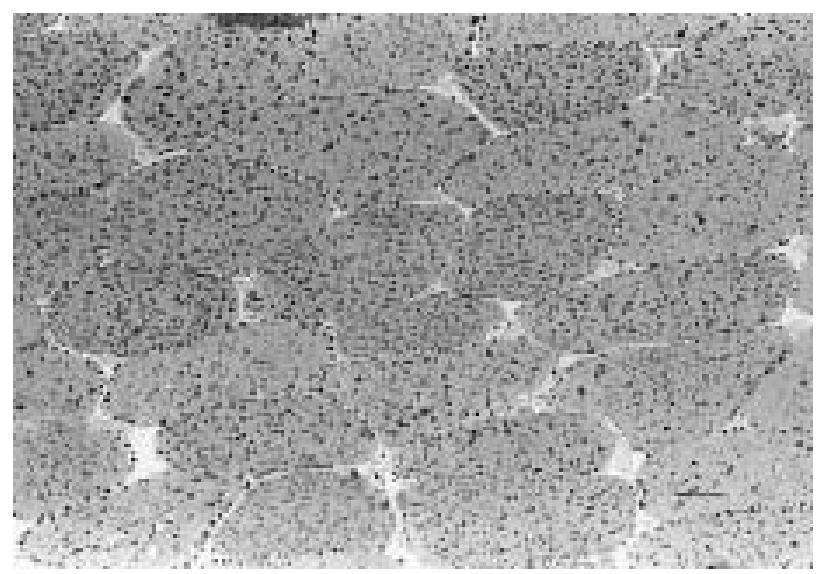

Fig. 2. - Photomicrograph of muscle biopsy. Muscle fibres contain increased numbers of large lipid granule (Oil-Red-O stain). (Internal scale bar $=30 \mu \mathrm{m}$.)
Table 1. - Muscle biopsy biochemical enzyme assay

\begin{tabular}{lrl}
\hline Assay data & Results & $\begin{array}{c}\text { Reference } \\
\text { values }\end{array}$ \\
\hline Respiratory enzymes $\mu \mathrm{mol} \cdot \mathrm{min}^{-1} \cdot \mathrm{g}-1$ & & \\
$\quad$ Cytochrome c oxidase & 1.18 & $>1.41$ \\
Succinate-cytochrome c reductase & 0.72 & $>0.35$ \\
NADH dehydrogenase & 28.18 & $>14.22$ \\
NADH-cytochrome c reductase & 0.73 & $>0.52$ \\
Reference enzymes $\mu \mathrm{mol} \cdot \mathrm{min}^{-1} \cdot \mathrm{g}^{-1}$ & & \\
$\quad$ Succinate dehydrogenase & 1.65 & $0.47-1.53$ \\
$\quad$ Citrate synthase & 8.01 & $7.33-12.43$ \\
Carnitine free nmol. $\mathrm{mg}^{-1}$ & 14.58 & $>9.00$ \\
Carnitine total nmol. $\mathrm{mg}^{-1}$ & 16.16 & $>10.25$ \\
\hline
\end{tabular}

Therapy included noninvasive ventilatory support with BiPAP (Respironics Inc, Murrysville, PA, USA), oxygen support and diuretics. This resulted in a progressive decrease in $P$ a, $\mathrm{CO}_{2}$ (from $>10.6 \mathrm{kPa}(80 \mathrm{~mm} \mathrm{Hg}$ ) to $<6.7 \mathrm{kPa}$ $(50 \mathrm{mmHg})$ ), and a gradual improvement in her FEV1 and FVC by $20 \%$. The patient was also symptomatically improved, noticing increased energy and decreased dyspnoea on exertion. A follow-up in the clinic 2 months later revealed a $\mathrm{Pa}, \mathrm{O}_{2}$ of $10.9 \mathrm{kPa}(82 \mathrm{mmHg}), \mathrm{Pa}_{\mathrm{a}} \mathrm{CO}_{2}$ of $6.0 \mathrm{kPa}$ (45 mmHg) on room air, and no evidence of pulmonary hypertension or right ventricular dilatation on a repeat cardiac ultrasound. Her MIP, measured at RV, was -118 $\mathrm{cmH}_{2} \mathrm{O}$, and her maximum expiratory pressure (MEP), measured at total lung capacity (TLC), was $110 \mathrm{cmH}_{2} \mathrm{O}$. At 12 months, using BiPAP $12 \mathrm{~h} \cdot$ day $^{-1}$ (inspiratory positive airway pressure $15 \mathrm{cmH}_{2} \mathrm{O}$, expiratory positive airway pressure $5 \mathrm{cmH}_{2} \mathrm{O}$ ), her pulmonary function tests demonstrated a FVC $1.66 \mathrm{~L}$ (42\% pred), FEV1 1.38 L (44\% pred), $\mathrm{FEV} 1 / \mathrm{FVC} \% 83 \%$ pred, and her $\mathrm{S} \mathrm{a}, \mathrm{O}_{2}$ saturation on room air was $99 \%$. The patient reported walking 1 mile $\cdot$ day $^{-1}$ and working $40 \mathrm{~h} \cdot$ week $^{-1}$.

\section{Discussion}

COX is one of four enzyme complexes in the mitochondrial respiratory chain (Complex IV) that transfer electrons from energy-rich molecules, such as nicotinamide adenine dinucleotide (NADH) and flavin adenine dinucleotide $\left(\mathrm{FADH}_{2}\right)$, to molecular oxygen. $\mathrm{COX}$ is located in the inner membrane of mitochondria. It is a complex enzyme composed of 13 subunits, three of which are coded by mitochondrial doexyribonucleic acid (DNA). The other 10 subunits are encoded by nuclear DNA. Because of its complexity, deficiency of this enzyme results in a variety of clinical presentations. They can be classified into two major groups: one with predominantly muscle involvement (myopathies), and the other with multisystem involvement predominantly affecting the brain (encephalomyopathies).

The patients with predominant muscle involvement usually present soon after birth with severe generalized weakness, respiratory distress and lactic acidosis. Some of them progressively deteriorate and die of respiratory failure before $1 \mathrm{yr}$ (fatal infantile myopathy). Others have renal involvement, or may initially have severe weakness and require ventilatory support, later improving spontaneously and usually normalizing by $2-3$ yrs of age (benign infantile myopathy). The presence of tissue-specific and developmentally regulated COX isoenzymes is a possible explanation for this return of COX activity [1-3]. 
Mitochondrial enzyme deficiencies are rare. Rarer still is the symptom onset in adults with no preceding respiratory symptoms, as in our patient. Most cases of COX deficiency are detected in infancy $[4,5]$, though there have been case reports in older children [6]. Presentation during adulthood has been previously reported [7-11], usually with either preceding lifelong respiratory symptoms or other chronic symptoms.

Ragged red fibres are typically seen in muscle biopsies of patients with mitochondrial myopathies (related to sub-sarcolemmal accumulation of abnormal mitochondria), though their presence is not absolute $[8,9]$. Ragged red fibres were seen in our patient, as evidenced by the very coarse, clumped mitochondrial staining in the majority of type I and type II muscle fibres. The normal extremity muscle EMG initially suggested a nonneuromuscular aetiology of respiratory failure. This has been previously reported, however [7, 9].

Sleep is thought to play a pivotal role in the evolution of respiratory failure in patients with neuromuscular disorders [12]. In general, the onset of respiratory failure begins as hypoventilation during rapid eye movement (REM) sleep. The resultant severe hypoxemia contributes to depression of the respiratory drive and arousability. This hypoventilation gradually extends into nonREM sleep and finally is also present during the awake state [13]. The weak respiratory muscles contribute partly or wholly to this sleep-disordered breathing, though other possible contributing factors include upper airway dysfunction, or impaired ventilatory control mechanisms due to brainstem involvement by the primary disease process. Treatment of this sleep-disordered breathing in patients with neuromuscular weakness with noninvasive positive pressure ventilation has been shown to improve awake daytime blood gas tensions and respiratory muscle strength significantly, thus altering the natural history of the disease [14]. This improvement may be secondary to relieving respiratory muscle fatigue or to improved central respiratory drive.

Our patient had both nocturnal and daytime hypoventilation. She was treated with BiPAP, initially on a continuous basis and eventually only at night. She showed an excellent response to this therapy, with improvements in her blood gas tensions, spirometry, and respiratory muscle strength. Presently, she is walking 1 mile.day ${ }^{-1}$, and has also started working a $40 \mathrm{~h}$ week. This patient's improved clinical and respiratory muscle function may be related to several factors, including treatment of sleep disordered breathing and relief of hypoxaemia with nocturnal BiPAP, and "unloading" of the respiratory muscles using daytime BiPAP promoting return to aerobic metabolism. It is also possible that this patient was malnourished due to her poor oral intake and higher metabolic demands secondary to her progressive dyspnoea. Treatment of this malnutrition, a condition known to exacerbate muscle weakness in mitochondrial and metabolic myopathies, may also have contributed to the patient's clinical improvement. Other potential therapies for treatment of muscle weakness due to COX deficiency include coenzyme Q10, aerobic training and dichloroacetate [9-11].
There are many instructive features in this patient. Firstly, neuromuscular weakness can cause respiratory failure and pulmonary arterial hypertension. Secondly, the need to consider neuromuscular aetiologies in patients with dyspnoea is reinforced. Finally, the effectiveness of bilevel positive airway pressure therapy in respiratory failure due to a myopathy is illustrated.

\section{References}

1. Zeviani M, Peterson P, Servidei S, Bonilla E, DiMauro S. Benign reversible muscle cytochrome c oxidase deficiency: a second case. Neurology 1987; 37: 64-67.

2. Servidei S, Bertini E, Dionisi-Vici C, et al. Benign infantile mitochondrial myopathy due to reversible cytochrome c oxidase deficiency: a third case. Clin Neuropathol 1988; 7: 209-210.

3. Salo MK, Rapola J, Somer H, et al. Reversible mitochondrial myopathy with cytochrome c oxidase deficiency. Arch Dis Child 1992; 67: 1033-1035.

4. Heiman PT, Bonilla E, DiMauro S, Foreman J, Schotland DL. Cytochrome-c-oxidase deficiency in a floppy infant. Neurology 1982; 32: 898-901.

5. Cros D, Palliyath S, DiMauro S, Ramirez C, Sharnsnia M, Wizer B. Respiratory failure revealing mitochondrial myopathy in adults. Chest 1992; 101: 824-828.

6. DiMauro S, Mendell JR, Sahenk Z, et al. Fatal infantile mitochondrial myopathy and renal dysfunction due to cytochrome-c-oxidase deficiency. Neurology 1980; 30: 795-804.

7. Haller RG, Lewis SF, Estabrook RW, DiMauro S, Servidei S, Foster DW. Exercise intolerance, lactic acidosis, and abnormal cardiopulmonary regulation in exercise associated with adult skeletal muscle cytochrome c oxidase deficiency. J Clin Invest 1989; 84: 155-161.

8. Hooper RG, Thomas AR, Kearl RA. Mitochondrial enzyme deficiency causing exercise limitation in normalappearing adults. Chest 1995; 107: 317-322.

9. Nozaki H, Hamano S, Ueoka Y, Horita H, Koga Y, Nonaka I. Cytochrome c oxidase deficiency with acute onset and rapid recovery. Pediatr Neurol 1990; 6: 330-332.

10. Ohno M, Kobayashi T, Tanaka K, Goto I, Nonaka I. Mitochondrial encephalomyopathy (focal cytochrome c oxidase deficiency) with transient episodes of muscle weakness and elevation of scrum creatine kinase activity. Rinsho Shinkeigaku 1990; 30: 317-319.

11. Taivassalo T, Matthews PM, De Stefano N, et al. Combined aerobic training and dichloroacetate improve exercise capacity and indices of aerobic metabolism in muscle cytochrome oxidase deficiency. Neurology 1996; 47: 529-534.

12. Piper AJ, Sullivan CE. Sleep-disordered breathing in neuromuscular disease. New York, Dekker, 1994; pp. 761786.

13. Bye PTP, Ellis ER, Issa FG, Donnelly PM, Sullivan CE. Respiratory failure and sleep in neuromuscular disease. Thorax 1990; 45: 241-247.

14. Ellis ER, Bye PTP, Bruderer JW, Sullivan CE. Treatment of respiratory failure during sleep inpatients with neuromuscular disease. Am Rev Respir Dis 1987; 135: 148152. 